\title{
Redactioneel
}

\section{Geen komkommertijd in het mededingingsrecht}

\author{
Anna Gerbrandy*
}

Geen komkommertijd de afgelopen zomer als het gaat om mededingingsrechtelijk nieuws. Eerst kwam de langverwachte megaboete voor Google. Al snel daarna volgde de zoveelste aflevering van het feuilleton in het dieselschandaal. Der Spiegel rapporteerde dat Volkswagen, Daimler, BMW, Audi en Porsche gezamenlijk jarenlang elkaar troffen en daarbij afspraken maakten over 'Technik, Kosten, Zulieferer und sogar über die Abgasreinigung ihrer Dieselfahrzeuge'. ${ }^{1}$ Volkswagen meldde vorige zomer haar betrokkenheid bij het Bundeskartellamt; Daimler deed hetzelfde. ${ }^{2}$ De Commissie bevestigde bij het onderzoek betrokken te zijn. ${ }^{3}$ Onderdeel van de gesprekken tussen de autofabrikanten was in ieder geval ook de omvang van de AdBluetanks in dieselauto's; met de AdBluevloeistof wordt de uitstoot van schadelijke emissies van NOx geneutraliseerd. Door op de afmeting van de tanks te bezuinigen werden kosten bespaard. Het scheelt ongeveer 80 euro per auto. Tegelijkertijd echter werden uitstootbeperkende maatregelen omzeild.
* Prof. mr. A. Gerbrandy is hoogleraar Mededingingsrecht aan de Universiteit Utrecht.

1. Der Spiegel, 21 juli 2017.

2. Onduidelijk is vooralsnog wie nu het eerst was: Der Spiegel stelt dat Volkswagen het initiatief nam; de Financial Times stelt dat Daimler eerst was ('Cartel Scandal puts German business culture on the line', Financial Times, 30 juli 2017). De Financial Times rapporteert bovendien dat het onduidelijk is of het om een clementieverzoek gaat.

3. 'EU Antitrust regulators say probing possible German car cartel', Reuters, 22 juli 2017.

\section{Vraagtekens bij Google}

De Google-zaak is juridisch boeiender dan het Volkswagenkartel. ${ }^{4}$ De Commissie stelt vast dat artikel 102 VWEU is overtreden. Google maakt misbruik van haar machtspositie als zoekmachine door de eigen prijsvergelijkingsdienst (comparison shopping-service) te bevoordelen. ${ }^{5}$ De eigen dienst werd bovenaan zichtbaar in zoekresultaten, terwijl vergelijkbare diensten een minder zichtbare plaats kregen. Dat levert de concurrenten minder kliks op. Dat heeft een negatief effect op keuzemogelijkheden van de Europese consument en op innovatie.

$\mathrm{Na}$ de bekendmaking van de boetebeschikking barstte de discussie, met name op internet, los over de vraag of de toepassing van het misbruikverbod door de Commissie in de Google-zaak nieum is, of oude wijn toegepast in een nieuwe context. Dat omvat een aantal elementen: onder welke juridische maatstaf de handelwijze van Google misbruikelijk zou zijn en (samenhangend) wat nu precies het consumer harm is. Om met dat eerste te beginnen: het is vooralsnog onduidelijk welke juridische maatstaf de Commissie nu precies heeft gebruikt. Tenzij sprake is van een essentiële faciliteit - het persbericht noemt dat niet - is het onduidelijk waarom een verticaal geintegreerde onderneming haar eigen dienst of haar eigen producten of dochterondernemingen niet zou mogen voortrekken. Het kan ook zijn dat het misbruik ligt in de koppeling van verschillende diensten, hetgeen heeft geleid tot afscherming van de markt voor concurrenten. Aanwijzing hiervoor is te vinden in het persbe-

Voor de duidelijkheid: ik heb de beschikking van de Commissie niet. Ik ben op geen enkele wijze betrokken bij de Google-zaak, behalve als geïnteresseerde academica.

5. Persbericht: http://europa.eu/rapid/press-release_IP-17-1784_nl.htm. 
richt, aangezien de Commissie stelt dat 'het verkeer naar (...) Google aanzienlijk is toegenomen, terwijl concurrenten blijvend te maken kregen met een zeer aanzienlijke afname van het verkeer'. Mogelijkerwijs doet de Commissie een beroep op de plicht (voor ondernemingen met een machtspositie) tot gelijke behandeling, als neergelegd in artikel $102 \mathrm{sub}$ c. Zij draagt Google immers op 'het eenvoudige beginsel van gelijke behandeling (...) na te leven'. ${ }^{6}$ De vraag of er sprake is van een nieuwe toepassing van een bestaand leerstuk of een nieuw leerstuk in het leven wordt geroepen, kan dus pas beantwoord worden nadat de beschikking van de Commissie is gepubliceerd. Wat precies de negatieve effecten van de handelwijze van Google zijn, is onderdeel daarvan. Vanwege het ontbreken van consumer harm had de Federal Trade Commission (FTC) juist een nader onderzoek naar Googles activiteiten afgewezen. ${ }^{7}$ Werd consumenten daadwerkelijk een keuze onthouden of zijn concurrenten slechts 'one click away'?8 Wordt consumenten niet juist een bétere dienst verleend doordat ze na een zoekopdracht een universal search result krijgen? ${ }^{9}$ Hier is van belang dat de Commissie echter niet alleen het bovenaan plaatsen van de eigen dienst als misbruikelijk gedrag aanwijst, maar ook het ver naar achter plaatsen van de concurrerende diensten. Dat kan erop wijzen dat het in ieder geval technisch mogelijk was om die resultaten wel degelijk in de 'box' op te nemen, en dat consumenten een daadwerkelijke keuze werd ontzegd. ${ }^{10}$

De Google-zaak - eigenlijk: de Google-zaken - hebben (indirect) ook betrekking op de relatie tussen mededingingsrecht en 'Big Data'. ${ }^{11}$ Over die relatie verscheen

6. Vóór het persbericht hierover o.a.: N. Petit, 'Theories of Self-Preference under article 102 TFEU: A Reply to Bo Vesterdorf', <https://papers.ssrn. com/sol3/papers.cfm?abstract_id=2592253>; P. Ibañez Colomo, 'Exclusionary Discrimination under Article 102 TFEU', Common Market Law Review 2014, 51, p. 141-164; P. Akman, 'The Theory of Abuse in Google Search', <https://papers.ssrn.com/sol3/papers.cfm?abstract_id= 2811789>. Ná het persbericht intelligente discussie o.a. op <https:// chillingcompetition.com/2017/06/27/google-shopping-decision-firsturgent-comments/>; <https://truthonthemarket.com/2017/06/29/afew-thoughts-on-the-european-commission-decision-against-google/>; $<$ https://truthonthemarket.com/2017/06/28/the-european-

commissions-regrettable-june-27-google-antitrust-decision-and-itsbroader-implications/>; <https://developingworldantitrust.com/2017/ 07/25/your-guide-to-the-google-shopping-decision/>; <http://lawpro fessors.typepad.com/antitrustprof_blog/2017/06/pinar-akman-initialreactions-to-the-infringement-decision-in-google-search.html>

7. Zie <www.ftc.gov/news-events/press-releases/2013/01/google-agrees -change-its-business-practices-resolve-ftc $>$.

8. Zie o.a. R.H Bork en J. G. Sidak, 'What Does the Chicago School Teach about Internet Search and the Antitrust Treatment of Google?', Journal of Competition Law \& Economics 2012, 8(4), p. 663-700; dat concurrentie 'one click away' is, wordt genuanceerd door o.a. A. Candeub, 'Behavioral Economics, Internet Search, and Antitrust', ISJLP 2014, 9, p. 407-434.

9. 'Universal' omdat er niet alleen een lijst van doorkliklinks wordt getoond, maar een direct resultaat in 'boxes' (zoals direct een kaart laten zien als je een adres zoek; of vertrektijden van de trein als je zoekt op een combinatie van twee plaatsnamen).

10. Over dit punt: <https://developingworldantitrust.com/2017/07/25/ your-guide-to-the-google-shopping-decision/>.

11. Het AdSense-onderzoek betreft restricties voor derdenwebsites in het weergeven van zoekadvertenties van Googleconcurrenten. Daarnaast speelt nog een derde Google-zaak: het Androidonderzoek betreft bundeling van het pre-installeren van Google Search en Google Chrome op Android-devices om toegang tot Google Play mogelijk te maken. recentelijk een rapport van Ecorys (in opdracht van de minister van Economische Zaken) waarin wordt geconcludeerd dat het mededingingsrecht gewoon kan worden toegepast op data-driven ondernemingen, zoals Google. ${ }^{12}$ Dat is een stuk minder alarmerend dan de recente roep om de macht van Google aan banden te leggen door haar in kleinere stukken op te breken. ${ }^{13} \mathrm{Het}$ Europese mededingingsrecht kan dat (in ieder geval vooralsnog) helemaal niet. ${ }^{14}$ Maar die roep lijkt dan ook te worden ingegeven door zorgen die het klassieke mededingingsrecht te buiten gaan: de combinatie van een immense beurswaarde, ${ }^{15}$ een uitdijend conglomeraat, en de koppeling van marktmacht aan datamacht (inclusief de beschikking over privacygevoelige data). ${ }^{16}$ Dat aanpakken via het mededingingsrecht zou wel degelijk nieuwe juridische maatstaven vergen.

\section{Vraagtekens bij Volkswagen}

Het Volkswagenkartel is om andere redenen interessant. ${ }^{17}$ Furidisch lijkt deze zaak niet erg ingewikkeld. Het bewijs van de langdurig mededingingsbeperkende afspraken dan wel onderling afgestemde feitelijke gedragingen, onder de vlag van de Duitse brancheorganisatie, zal met de clementieverzoeken van Volkswagen en Daimler niet lastig zijn. In het nieuws wordt het beeld opgeroepen van een klassiek kartel waarbij zakenlieden elkaar al rokend in achterkamers troffen en waarover Adam Smiths bekende citaat stelt: 'People of the same trade seldom meet together, even for merriment and diversion, but the conversation ends in a conspiracy against the public, or in some contrivance to raise prices.' Wel is, zoals vaker als het gaat om langlopende kartels, de vraag hoe het komt dat het systeem zo lang heeft kunnen voortbestaan. Het gaat hierbij - opnieuw: voor zover bekend - om zestig verschillende werkgroepen, meer dan tmeehonderd bij de overlegvormen betrokken bestuurders en werknemers, die elkaar meer dan twintig jaar lang spraken over een veelvoud aan onderwerpen. Kan dat tot de achterkamers beperkt zijn geble-

12. Ecorys (Harry van Til, Nicolai van Gorp, Katelyn Price), Big Data and Competition, 13 juni 2017: <www.rijksoverheid.nl/documenten/ rapporten/2017/06/13/big-data-and-competition>.

13. 'Is it Time to Break Up Google', New York Times, 22 april 2017, zie <www.nytimes.com/2017/04/22/opinion/sunday/is-it-time-to-breakup-google.html>

14. Zie mijn eerdere column in dit blad ('Paradigmaverschuivingen', M\&M 2016/4, p. 145-146) en meer recent, 5 mei 2017, 'Macht van Google is groot, maar wettelijk niet verboden', zie <www.nrc.nl/nieuws/2017/ 05/05/macht-van-google-is-groot-maar-wettelijk-niet-verbodena1557357>.

15. Op 31 mei 2017 waren Apple, Google/Alphabet, Microsoft, Amazon en Facebook bedrijven met de hoogste beurswaarde.

16. In het geval van Facebook komt daar de (kennelijke) persoonlijke ambitie van Zuckerberg bij om ook buiten het domein van zakelijke belangen zijn invloed te vergroten (zie: 'Imperial Ambitions', The Economist, 9 april 2015)

17. Ik ben ook bij deze zaak op geen enkele wijze betrokken. Hieronder makk ik een vergelijking met de bouwfraudezaak. Ik was raadsheerplaatsvervanger in zaak CBb 5 april 2012, [A] v. NMa, ECLI:NL:CBB: 2012:BW1393. 
ven? Er is aanleiding om aan te nemen dat dat niet het geval was en dat het bestaan van de werkgroepen in ieder geval binnen de auto-industrie een bekend gegeven was. ${ }^{18}$ Er zijn kennelijk sterke banden tussen de Duitse overheid en de auto-industrie (die nu kritisch tegen het licht worden gehouden), zodat het de vraag is of de overheid geheel onschuldig is in deze zaak. ${ }^{19}$

Zoals bekend bij de lezers van dit blad blijft - simpel gesteld - een kartel stabiel zolang de baten voor de betrokkenen opwegen tegen de kosten. Tegelijkertijd leert het klassieke prisoner's dilemma ons dat collusie in beginsel kwetsbaar is; met het in het leven roepen van een clementieregeling wordt de inherente onderlinge onzekerheid versterkt en de kwetsbaarheid van het voortbestaan van een kartel vergroot. Naar aanleiding van de Nederlandse bouwfraude - ook een langdurig complex van mededingingsbeperkende afspraken dat een groot deel van de sector betrof; ook ooit onder de paraplu van een brancheorganisatie tot stand gekomen is ook wel een aanvullend verklaringsmodel naar voren gebracht. Naast het antwoord op de vraag 'how much does anti-trust law matter', gelet op de incentives van collusie tegenover mogelijke sancties, is getracht de vraag ' $h o m$ does anti-trust law matter' te beantwoorden. ${ }^{20}$ Daarbij is de conclusie, op zich wellicht niet verassend, dat de cultuur in een bepaalde sector een bepalende factor is voor het bestaan en de inhoud van 'legal consciousness', en daarmee voor het naleven van (specifiek mededingingsrechtelijke) regelgeving. Het is dan de vraag of de cultuur in de Duitse auto-industrie op de (in ieder geval destijds heersende) cultuur in de Nederlandse bouwsector lijkt en aan de kenmerken voldoet van wat wel een 'eilandcultuur' is genoemd. Aanwijzingen (opnieuw: dat is op geen enkele manier bewijs van een overtreding) zouden kunnen zijn de hiervoor al genoemde innige relatie tussen industrie en overheid; ${ }^{21}$ de meer in het algemeen corporatistische bedrijfscultuur in Duitsland; een weinig geïnternaliseerde acceptatie van mededingingsregels (zoals blijkt uit de herinneringen van Bob Lutz, destijds CEO van General Motors, aan een ontmoeting met Daimlers CEO Joachim Zahn); ${ }^{22}$ en het kennelijk buiten de langdurig onderhouden onderlinge relaties houden van buitenstaanders General Motors en Ford. Al met al zijn dat aanwijzingen voor het bestaan van de 'eilandcultuur' waar Hertogh zijn studie naar de Nederlandse bouwfraude op baseerde. Daarmee kan dat een aanvullend perspectief bieden op hoe een complex systeem van overleg en afspraken zo lang kan hebben blijven voorbestaan.

18. 'Dieselgate Product of Vast VW-BMW-Daimler Car Cartel Conspiracy, Fresh Report Says', Forbes, 22 juli 2017

19. 'Cartel Scandal puts German business culture on the line', Financial Times, 30 juli 2017. Zie ook <www.dw.com/en/made-in-germanycartel-collusion-not-a-peccadillo/av-39907909>

20. M. Hertogh, 'Crime and Custom in the Dutch Construction Industry. A socio-legal Case study of Self-regulation', 2010; o.a. te vinden via <https://papers.ssrn.com/sol3/papers.cfm?abstract_id=1532182>

21. Zie hierover Forbes (hierboven aangehaald) waarin wordt gememoreerd dat een oud-minister van Transport aan het hoofd van de brancheorganisatie staat.

22. In: B. Lutz, Icons and Idiots, Penguin 2013.

\section{En nog meer interessants...}

In de schaduw van Google en Volkswagen is nog meer interessant mededingingsnieuws te vinden: een nieuwe pay-for-delay-zaak (de vierde alweer); ${ }^{23}$ een onderzoek naar verticale restricties in e-commerce. ${ }^{24}$ In Nederland liet de ACM al eerder van zich spreken met een boete opgelegd aan de NS en - na de 'marktscan' over de havensector - de ankondiging van een onderzoek naar een mogelijk kartel in de bunkersector (de opslag van olieproducten; ik moest ook even nazoeken wat deze betekenis van het woord 'bunker' is). ${ }^{25}$ De ACM en het Bundeskartellamt als dappere ridders van 'Queen Margrethe'? ${ }^{26}$ Vestager is in ieder geval niet bang om zowel grote Amerikaanse draken als gevestigde Europese reuzen aan te pakken. In dit blad zijn de auteurs evenmin angstig. In dit nummer allereerst aandacht voor het nieuwe mededingingsrecht van Curaçao (van de hand van Sjoerd Bakker), een prikkelende column van onze nieuwe columnist Matthijs Visser over het de rol van het Economisch Bureau in transparantie van economische bewijsvergaring, en lezenswaardige annotaties bij uitspraken van vier verschillende instanties: van Maarten Aalbers bij het arrest van het Hof in de zaak Viasat, over artikel 106 lid 2 TFEU en Altmark; van Nienke de Jong bij het arrest van het Gerecht in de zaak Infineon over de enkele voortdurende inbreuk; van Floris ten Have bij een uitspraak van de Rechtbank Den Haag over digitale bewijsgaring; en van Frank Cornelissen en Sjaak van der Heul bij een uitspraak van de Rechtbank Rotterdam over de onderzoeksverplichting van de ACM bij toepassing van de bagatelbepaling.

23. Press release 17 juli 2017 , zie <http://europa.eu/rapid/press-release_IP -17-2063_en.htm>.

24. Press release 6 juni 2017, zie <http://europa.eu/rapid/press-release_IP -17-1549_en.htm>.

25. NS, zie <www.acm.nl/nl/publicaties/publicatie/17379/Boete-NS-voormisbruik-machtspositie-bij-Limburgse-aanbesteding/>; marktscan, zie $<$ www.acm.nl/nl/publicaties/publicatie/16729/ACM-heeft-zorgen-over -kennis-en-naleving-concurrentieregels-in-havens/>; bunkersector, zie $<$ www.acm.nl/nl/publicaties/publicatie/17450/ACM-start-onderzoeknaar-mogelijk-kartel-in-bunkersector/>.

26. 'The European Commission levies a huge fine on Google', The Economist, 1 juli 2017. 